\title{
Effect of the Notch1-mediated PI3K-Akt-mTOR pathway in human osteosarcoma
}

\author{
Kexiang Zhang ${ }^{1}$, Song $\mathrm{Wu}^{1}$, Hongwei $\mathrm{Wu}^{2}$, Li Liu${ }^{1}$, Jiahui Zhou ${ }^{1}$ \\ ${ }^{1}$ Department of Orthopedics, Third Xiangya Hospital, Central South University, Changsha 410013, Hunan Province, \\ China \\ ${ }^{2}$ Department of Orthopedics, Hunan Cancer Hospital and The Affiliated Cancer Hospital of Xiangya School of \\ Medicine, Central South University, Changsha 410013, Hunan Province, China
}

Correspondence to: Song Wu; email: 600240@csu.edu.cn

Keywords: osteosarcoma, Notch1, autophagy, PI3K/Akt/mTOR

Received: February 20, $2020 \quad$ Accepted: November 10, 2020

Published: September 8, 2021

Copyright: (c) 2021 Zhang et al. This is an open access article distributed under the terms of the Creative Commons Attribution License (CC BY 3.0), which permits unrestricted use, distribution, and reproduction in any medium, provided the original author and source are credited.

\section{ABSTRACT}

Purpose: Osteosarcoma is one of the most common malignant bone tumours in early adolescence. The incidence rate of osteosarcoma has stagnated over the past $\mathbf{3 0}$ years, highlighting the need to develop novel therapies. In osteosarcoma cells, Notch1 expression is absent, and the Notch1 pathway is related to cancer cell proliferation, apoptosis and autophagy. Our study aimed to investigate the role of Notch1 in osteosarcoma development.

Methods: We measured NICD1 expression induced by doxycycline treatment at various concentrations. The viability of human osteosarcoma cells (MG-63) induced by doxycycline was measured. Flow cytometry and cell apoptosis analysis were conducted to measure the effect of Notch1 on the cell cycle of human osteosarcoma cells. We also used a GFP-LC3 plasmid to detect Notch1-induced autophagy in MG-63 cells. Western blotting was conducted to analyse expression of the PI3K/Akt/mTOR signalling pathway through Notch1 induction by doxycycline.

Results: In this study, we demonstrated that Notch1 activation by doxycycline potently suppressed cell proliferation by inducing $\mathrm{S}$ phase arrest in osteosarcoma cells. Doxycycline-induced Notch1 activation also induced apoptosis and autophagy in osteosarcoma cells. Moreover, we found that Notch1 inhibited $\mathrm{PI3K} / \mathrm{Akt} / \mathrm{mTOR}$ signalling to induce apoptosis and autophagy.

Conclusion: In summary, our results revealed that Notch1 activation by doxycycline induces $S$ phase arrest, apoptosis and autophagy by blocking PI3K/Akt/mTOR signalling in human osteosarcoma cells. Notch1 may be a potential clinical antitumour target for osteosarcoma therapy.

\section{INTRODUCTION}

Osteosarcoma (OS) is the most common primary bone malignancy in children and adolescents [1]. Half of osteosarcoma patients have pulmonary metastases due to early metastases. Because of its life-threatening nature, the relatively low incidence does not fully reflect the real burden of OS on patients and communities [2]. Preoperative inductive and postoperative immunogenic chemotherapy have significantly increased the 5-year survival rate from $20 \%$ to $70 \%$ [3]. However, the survival rate has remained almost unchanged for three decades since the introduction of multi-drug chemotherapy [4].

Autophagy is the primary means by which eukaryotes have evolved to degrade autologous organelles or proteins [5], regulating and controlling cell proliferation and function. Increasing studies have shown that autophagy plays an important role in the development 
of malignant tumours [6]. Microtubule-associated protein 1 light chain 3 (LC3), which is located at the membrane surface of the pre-autophagosome and autophagosome, is usually used as a specific marker of autophagy [7]. Beclin-1 is also regarded as a marker of autophagy and inhibits tumour growth through the enhancement of autophagy [8]. In addition, the phosphatidylinositol 3-kinase/Akt/mTOR signalling pathway plays an important role in tumour cell proliferation, apoptosis, autophagy, relapse and metastasis, as well as the degradation of the extracellular matrix [9]. Hence, drugs inhibiting $\mathrm{PI} 3 \mathrm{~K} / \mathrm{Akt} / \mathrm{mTOR}$ are increasingly valued in tumour research.

The Notch family (Notch1-4) of heterodimeric transmembrane receptors regulates cell differentiation, proliferation, and apoptosis and plays a critical role in development [10]. Increasing evidence demonstrates that Notch1 regulates PI3K-Akt-mTOR signalling in tumours, although many details are still emerging [11]. In MDA-MB-231 cells, in which Notch1 is constitutively activated, p-Akt is upregulated, indicating activation of the PI3K/Akt pathway [12]. The mammalian target of rapamycin complex (mTOR) pathway is a major point of convergence of Notch1 and PI3K-Akt signalling and promotes the growth of T-ALL cells [13-15].

There is still controversy regarding the role of autophagy in tumour treatment [16], and the inhibitory and protective effects of autophagy during tumour treatment need to be further elaborated. In the present study, human osteosarcoma cell lines were treated with a Notch1 inducer, and changes in cell proliferation, the cell cycle and autophagy were analysed. The aim was to investigate changes in autophagic activity and the molecular mechanism of Notch1-mediated $\mathrm{PI} 3 \mathrm{~K} / \mathrm{Akt} / \mathrm{mTOR}$ signalling during autophagy to provide a theoretical basis for the treatment of osteosarcoma.

\section{RESULTS}

\section{Notch1 inhibits osteosarcoma cell viability}

To ensure that TT-NOTCH1 cells expressed functional Notch1 protein in response to doxycycline treatment, we carried out an experiment before proceeding to in vitro studies. As shown in Figure 1A, Notch1 protein (NICD1) expression of TT-NOTCH1 was significantly induced by doxycycline at $5 \mu \mathrm{M}$ and $10 \mu \mathrm{M}$. This result was consistent with a previous observation [10]. To investigate the anti-proliferative effect of Notch1 induced by doxycycline on osteosarcoma cells, human osteosarcoma MG-63-
Notch1 (TT-NOTCH1) cells were treated with doxycycline and analysed by MTT assays (Figure 1B). After treatment, the viability of osteosarcoma cells was significantly decreased in a dose-dependent manner, with an $\mathrm{IC}_{50}$ value of $7.60 \mu \mathrm{M}$. This result showed that Notch1 activated by doxycycline inhibited osteosarcoma cell proliferation in a dosedependent manner.

\section{Notch1 induces cell cycle arrest at $S$ phase}

The cell cycle arrest via doxycycline-induced Notch1 is shown in Figure 2. After treatment with doxycycline at $10 \mu \mathrm{M}$ for $12,24,36,48,60 \mathrm{~h}$, based on previous experiments (data not shown), the percentages of $\mathrm{S}$ phase cells were $35.85 \%, 32.65 \%, 26.31 \%, 24.89 \%$, $20.66 \%$ and $18.56 \%$, respectively. These results show that doxycycline upregulates the expression of Notch1 over time, which inhibits the rate of cell proliferation by decreasing the percentage of $S$ phase cells.

\section{Notch1 induces apoptosis of osteosarcoma cells}

Apoptosis induced by Notch1 was further investigated through a Dead Cell Apoptosis Kit (Invitrogen) containing recombinant Annexin V conjugated to FITC and a ready-to-use solution of red-fluorescent propidium iodide (PI) nucleic acid binding dye. As shown in Figure 3, osteosarcoma cells were found to exhibit different degrees of cell shrinkage, chromatin condensation and nuclear fragmentation after treatment with $10 \mu \mathrm{M}$ doxycycline for $12,24,36,48$, and $60 \mathrm{~h}$. Annexin V-FITC/PI double staining demonstrated that osteosarcoma cells activated the Notch1 pathway in a time-dependent manner after treatment with doxycycline in both early and late apoptotic cells, in which the proportion of apoptotic cells increased from $5.3 \%$ to $33.8 \%$.

In advanced experiments, we analysed the effect of shNotch1 treatment on TT-NOTCH1 cells. It was found that shNotch1 could upregulate the apoptosis rate and improve cell colony formation (Figure 4A, 4B).

\section{Notch1 activates autophagy in osteosarcoma cells}

We then determined whether Notch1 induced by $10 \mu \mathrm{M}$ doxycycline could induce autophagy in osteosarcoma cells. The results showed that the average number of GFP-LC3 puncta per cell was 4.6, 23.4, 32.2, 35, 37.2 and 42.2, which suggested that treatment of osteosarcoma cells with doxycycline resulted in a significant increase in GFP-LC3 puncta formation (Figure 5). Furthermore, we investigated the expression of autophagy-related proteins by Western blotting. The results showed that doxycycline-induced Notch1 
increased the levels of LC3B-II and Beclin-1 in osteosarcoma cells in a time-dependent manner.

\section{Notch1 blocks the PI3K/Akt/mTOR signalling pathway}

Western blot results showed that p-PI3K, p-Akt and pmTOR were significantly downregulated after doxycycline treatment compared to those of the control group (Figure 6). These data suggest that doxycyclineinduced Notch1 expression inhibits the PI3K/Akt/mTOR signalling pathway, which may be the molecular mechanism of apoptosis and autophagy. Compared with that of the control group, silencing Notch1 could lead to reduced expression of p-PI3K and
p-Akt; however, the silencing effect was not detected in the vector-only group (Figure 7).

\section{DISCUSSION}

Notch signalling plays important roles in determining cell fate during development and is activated upon cellto-cell contact as a result of interactions between Notch receptors and their ligands [17]. Ligand binding results in proteolytic cleavage of Notch receptors by $\gamma$ secretases, leading to the release of an $80-\mathrm{kDa}$ intracellular domain of Notch (NICD), which then translocates to the nucleus and activate the transcription of downstream target genes [18]. Our study showed that high expression of Notch1 positively correlated with
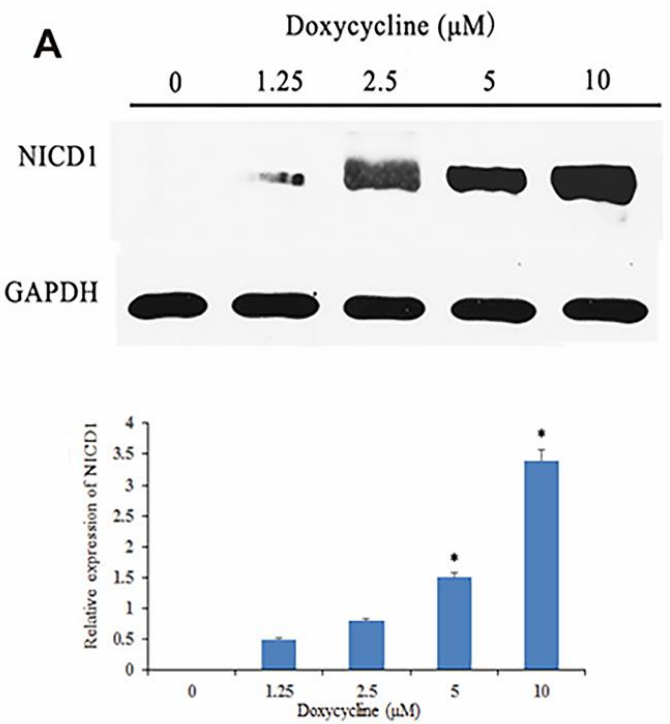

B

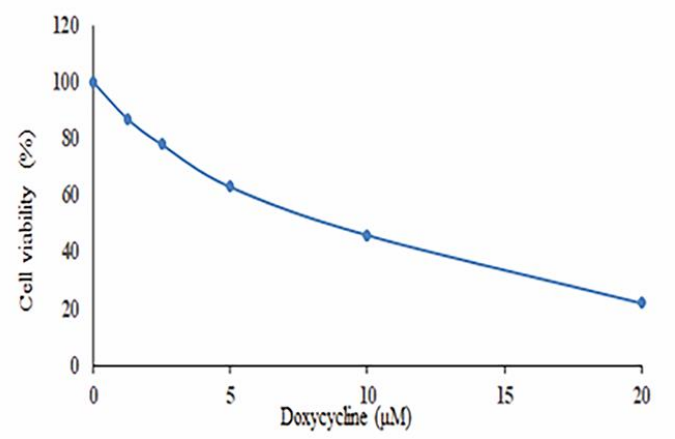

C

D
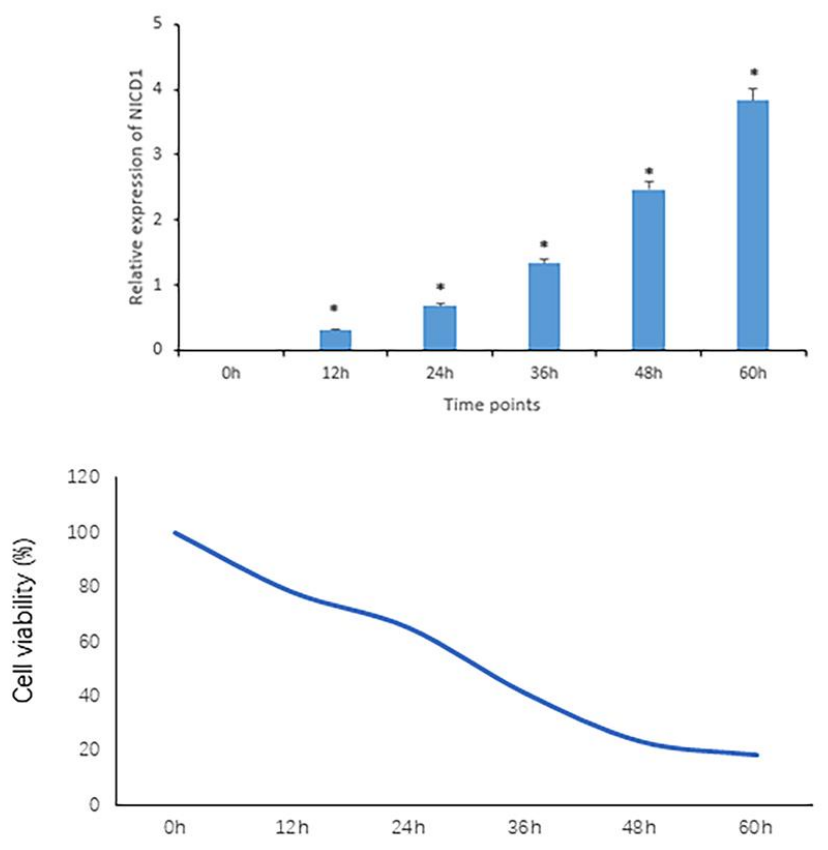

Figure 1. Notch1 expression and cell viability induced by doxycycline treatment. (A) The NICD1 expression induced by doxycycline treatment at various concentrations. GAPDH was used as loading control. ${ }^{*} \mathrm{P}<0.05$, significantly different compared with the untreated control group. (B) Notch1 induced by doxycycline in various concentrations has inhibited cell viability in human osteosarcoma cell (MG-63). All the experiments were conducted in triplicates. (C) The NICD1 expression induced by doxycycline treatment at various time points including $0 \mathrm{~h}, 12 \mathrm{~h}, 24 \mathrm{~h}, 48 \mathrm{~h}, 36 \mathrm{~h}$ and $60 \mathrm{~h}$. GAPDH was used as loading control. ${ }^{*} \mathrm{P}<0.05$, significantly different compared with the untreated control group. (D) Notch1 induced by doxycycline in various time points including $0 \mathrm{~h}, 12 \mathrm{~h}, 24 \mathrm{~h}, 48 \mathrm{~h}, 36 \mathrm{~h}$ and $60 \mathrm{~h}$ has inhibited cell viability in human osteosarcoma cell (MG-63). All the experiments were conducted in triplicates. 
active autophagy in human osteosarcoma cells. Upregulated Notch1 activated autophagy and cell death related to autophagy, which suggested the potential role of Notch1 in modulating the activity of autophagy.

To investigate the effect of Notch1 on osteosarcoma cell growth and autophagy, we developed an in vitro model of doxycycline-induced expression of NICD1 using the TET-ON system, which was based on the tetracyclinecontrolled transactivator protein tTA [19]. Our in vitro study showed that overexpression of NICD1 in osteosarcoma cells was significantly reduced by doxycycline treatment. Further results showed that overexpression of Notch1 could inhibit osteosarcoma cell proliferation and improve apoptosis and autophagy by regulating the $\mathrm{PI} 3 \mathrm{~K} / \mathrm{Akt} / \mathrm{mTOR}$ pathway.

The Notch pathway is critical for development and tissue homeostasis and consists of ligands, receptors, and intracellular signalling molecules. Notch signalling is abnormally activated in various cancers, such as leukaemia, and malignant solid tumours, such as lung, prostate, and breast cancers. Yao et al. reported that Notch1 activation induced cell cycle arrest and

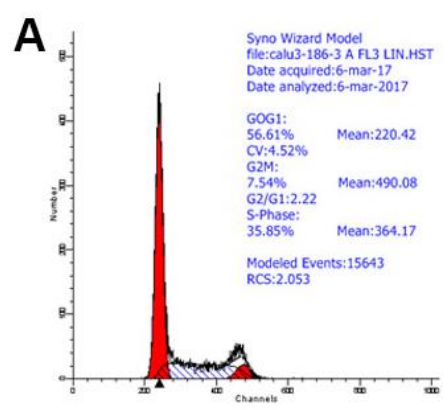

Control

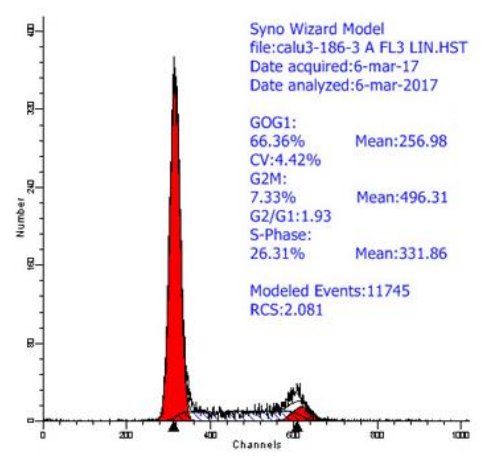

$24 \mathrm{~h}$ incubation

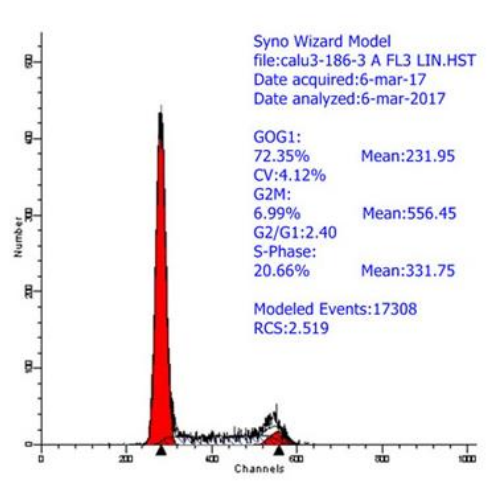

$48 \mathrm{~h}$ incubation

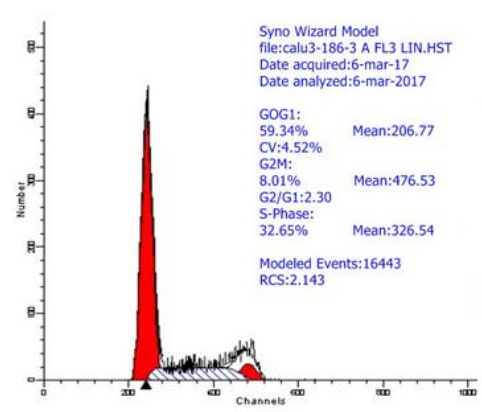

$12 \mathrm{~h}$ incubation
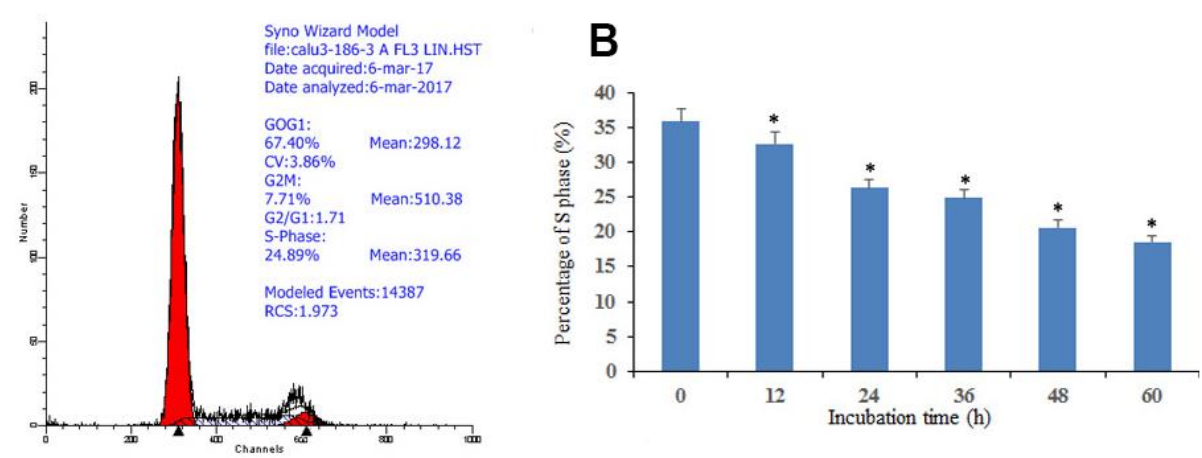

$36 \mathrm{~h}$ incubation

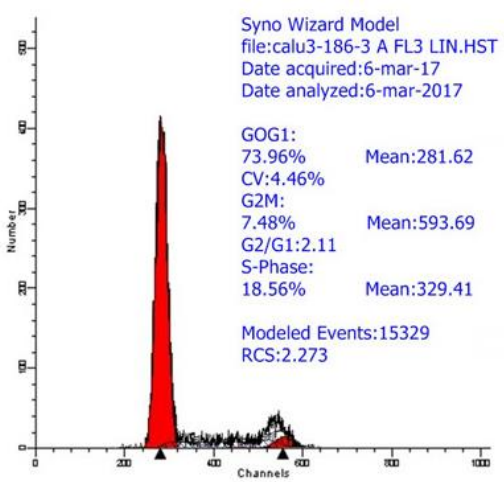

$60 \mathrm{~h}$ incubation

Figure 2. Notch1 induced S phase cycle arrest in human osteosarcoma cells. (A) Notch1 induced by doxycycline in different time induced S phase cell cycle arrest in human osteosarcoma cells. Cells were treated with doxycycline for $0,12,24,36,48$ and $60 \mathrm{~h}$ and analyzed by flow cytometry. The percentage of cell population at G1, S, and G2/M phases were represented as mean \pm SD of three independent experiments. (B) The histogram of percentage of $S$ phase in different groups. ${ }^{*} \mathrm{P}<0.05$, significantly different compared with the untreated control group. All the experiments were conducted in triplicates. 
apoptosis in human cervical cancer cells [20]. Greenblatt et al. showed that activating Notch1 signalling induced apoptosis in medullary thyroid cancer cells [21]. Zeng et al. suggested that the Notch1 signalling pathway may inhibit A549 cell growth by regulating cell cycle-related and anti-apoptotic protein expression by regulating the PI3K/Akt pathway [22].
The present study proves that Notch1 induces osteosarcoma apoptosis.

Apart from apoptosis, autophagy also plays a significant role in determining cell fate [23]. The present study showed that the Notch1 pathway could induce autophagy by upregulating LC3-II and Beclin-1
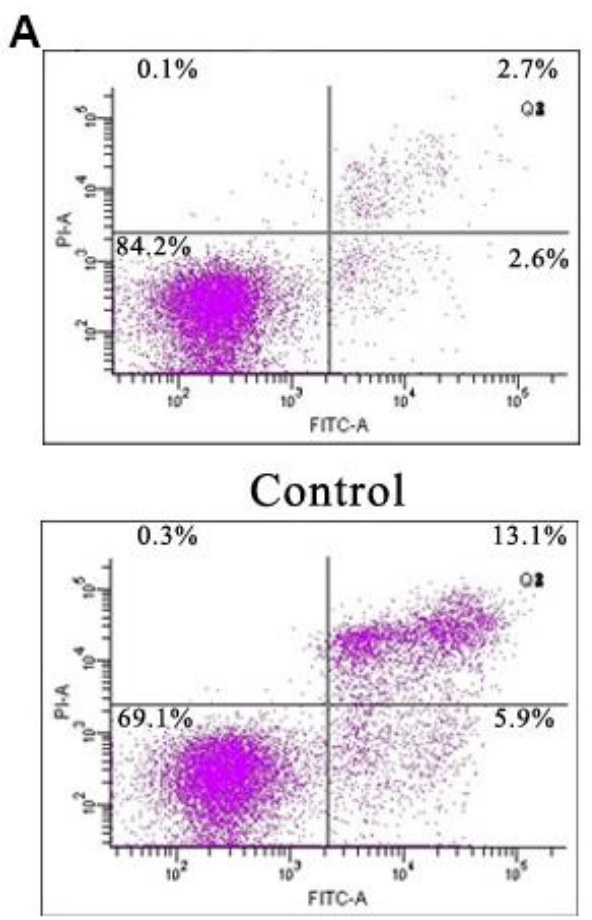

$36 \mathrm{~h}$ incubation

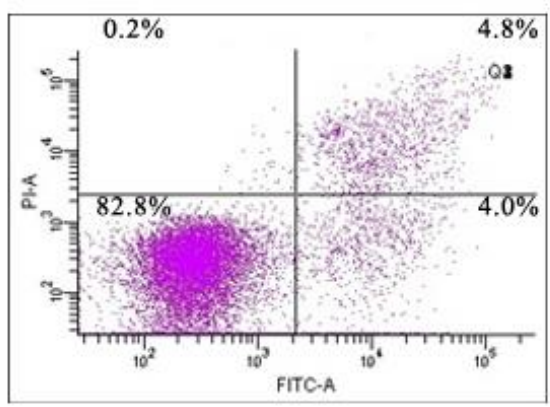

$12 \mathrm{~h}$ incubation

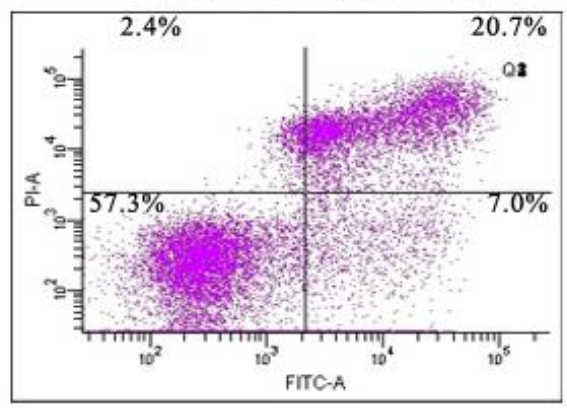

$48 \mathrm{~h}$ incubation
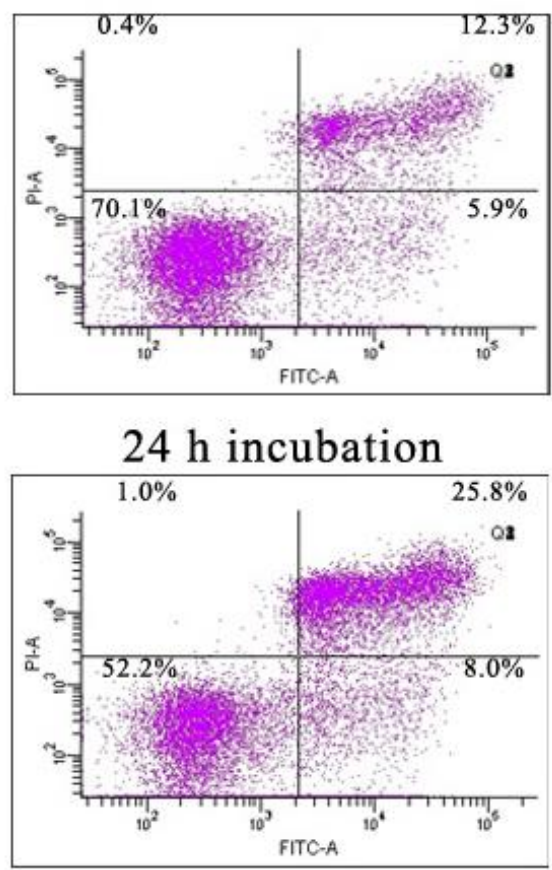

$60 \mathrm{~h}$ incubation

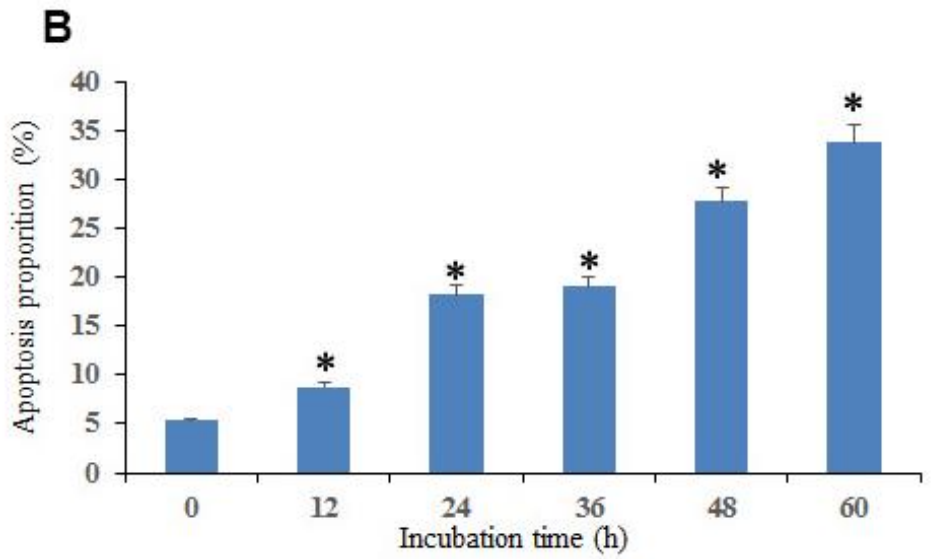

Figure 3. Notch1 induced osteosarcoma cell apoptosis. (A) Notch1 induced by doxycycline in different time induced osteosarcoma cell apoptosis. Cells were treated with doxycycline for $0,12,24,36,48$ and $60 \mathrm{~h}$ and analyzed using Annexin V-FITC/PI flow cytometry. (B) The histogram indicated that apoptosis proportion from three separate experiments in different groups. ${ }^{*} \mathrm{P}<0.05$, significantly different compared with the untreated control group. All the experiments were conducted in triplicates. 
expression. However, Yao et al. showed that the expression levels of LC3-II and Beclin-1 were significantly increased in Notch1 siRNA-transfected U251 cells, suggesting that cell autophagy was induced when Notch1 was downregulated in glioma cells [24]. These results were opposite to those of the present study. Thus, the relationship between the Notch1 pathway and cancer cell autophagy needs further confirmation.

Recent studies have shown that multiple signalling molecules are related to apoptosis and autophagy [25]. A close connection between autophagy and angiogenesis/apoptosis has also been demonstrated in osteosarcoma. A previous study revealed that tetrahydrocurcumin suppressed angiogenesis by targeting HIF- $1 \alpha$ and autophagy in human osteosarcoma cells [26]. In addition, $\mathrm{Li} \mathrm{HY}$ et al. reported that celastrol induced apoptosis and autophagy via the ROS/JNK signalling pathway in human osteosarcoma cells [27]. The PI3K/Akt/mTOR pathway is genetically targeted in many kinds of tumours, and it is frequently activated as a cancer driver. PI3K and Akt are vital mediators of carcinogenesis through phosphorylation. One major downstream effector of Akt signalling necessary for tumourigenesis is mTOR, which has also been reported to participate in the regulation of autophagy in mammalian cells [28]. Research has suggested that many monomers of traditional Chinese herbs play important roles in anticancer processes by inactivating the PI3K/Akt/mTOR pathway. For example, G2/M cell cycle arrest and apoptosis were induced by oridonin via the PI3K/Akt signalling pathway in hormone-independent prostate cancer cells [29]. Activation of PI3K/Akt signalling pathways antagonized sinomenine-induced lung cancer cell apoptosis [30].

Autophagy has a dual role in the regulation of cell death. Mild autophagy protects cells from harmful conditions, and severe or rapid autophagy induces programmed cell death, which is called autophagic cell death $[31,32]$. In previous studies, cooperation between autophagy and apoptosis was identified and was suggested to promote cell death [33, 34]. In this study, our data showed that doxycycline significantly increased cell autophagy, which indicated a synergistic role of autophagy death and apoptosis after doxycycline treatment. A previous study reported that doxycycline suppresses cell proliferation and matrix metalloproteinase (MMPs) activity and induces apoptosis in human osteosarcoma cells in vitro. This anti-proliferative activity of doxycycline is attributed to the inhibition of MMPs, enzymes involved in the

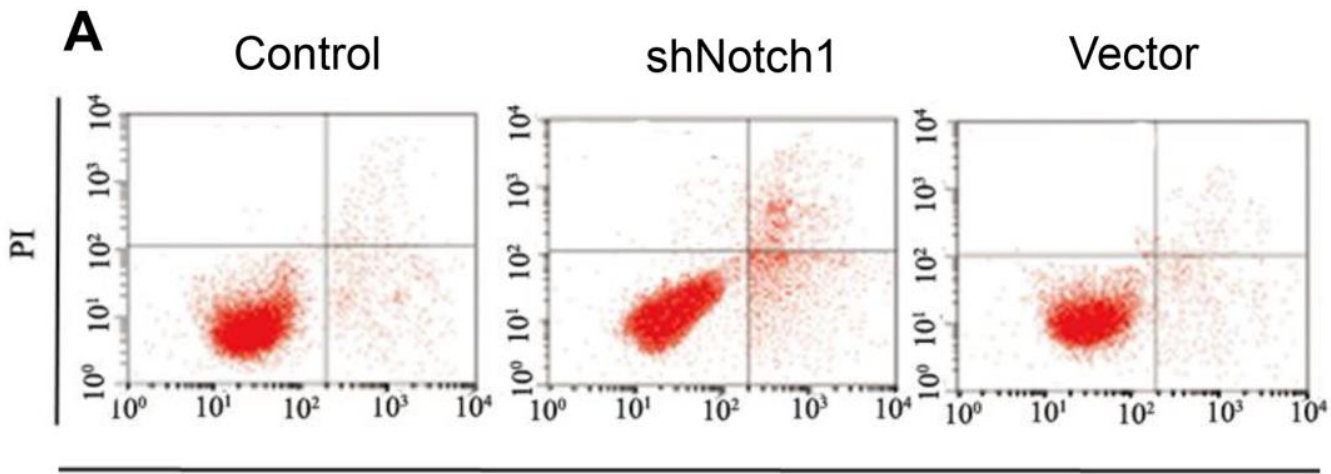

B

Annexin V-FITC

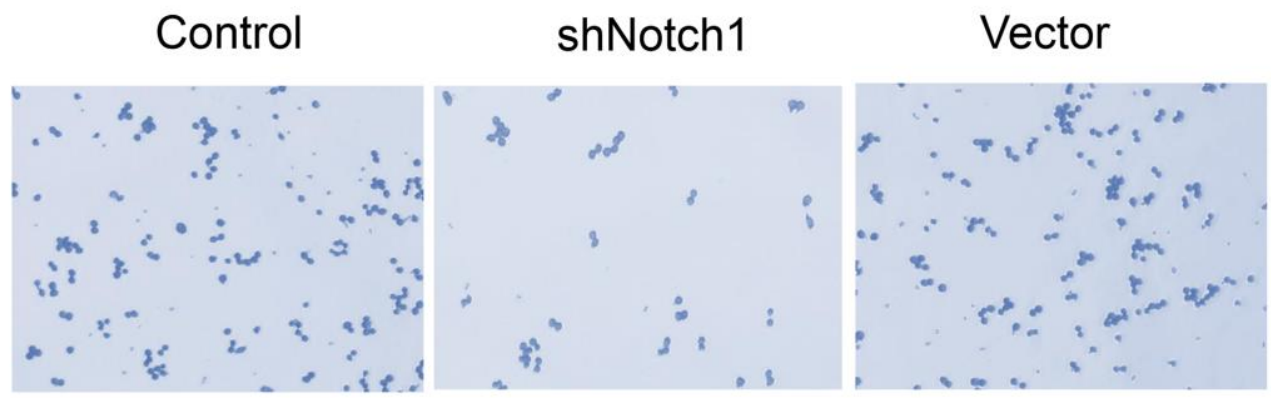

Figure 4. shNotch1 induced osteosarcoma cell apoptosis and cell proliferation. (A) shNotch1 treatment induced up-regulated osteosarcoma cell apoptosis. (B) shNotch1 treatment induced up-regulated osteosarcoma cell colony formation. 
degradation and remodelling of the extracellular matrix. Herein, the ability of doxycycline to inhibit MMPs and induce autophagy can represent new potential targets for the treatment and detection of cancer patients.

The present study showed that Notch1 inhibited the phosphorylation of PI3K, Akt and mTOR. Thus, $\mathrm{PI} 3 \mathrm{~K} / \mathrm{Akt} / \mathrm{mTOR}$ signalling is central to the Notch1 signalling pathway, suggesting that targeting $\mathrm{PI} 3 \mathrm{~K} / \mathrm{Akt} / \mathrm{mTOR}$ with small molecule inhibitors would show great promise in treating osteosarcoma. Better understanding of how Notch 1 regulates $\mathrm{PI} 3 \mathrm{~K} / \mathrm{Akt} / \mathrm{mTOR}$ would likely create novel therapeutic opportunities for targeting these important cellular pathways in osteosarcoma.

\section{CONCLUSIONS}

In conclusion, our study showed that Notch 1 activation could suppress cell proliferation by causing $\mathrm{S}$ phase

A

GFP-LC3

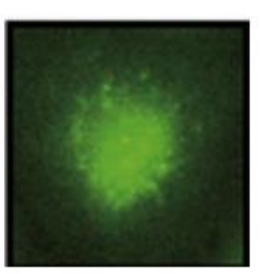

Control

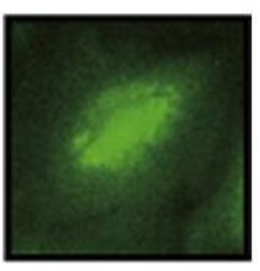

$12 \mathrm{~h}$ incubation

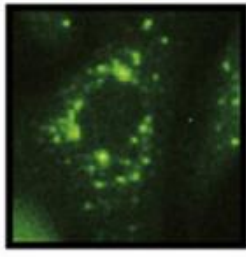

$24 \mathrm{~h}$ incubation

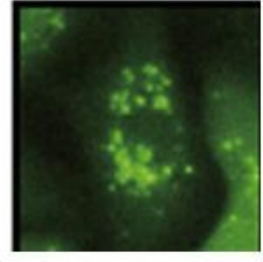

$36 \mathrm{~h}$ incubation

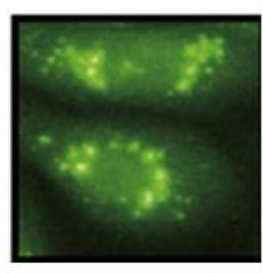

$48 \mathrm{~h}$ incubation

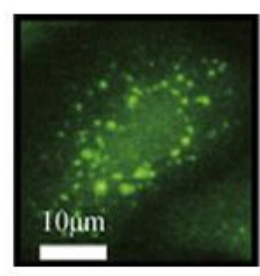

$60 \mathrm{~h}$ incubation
B

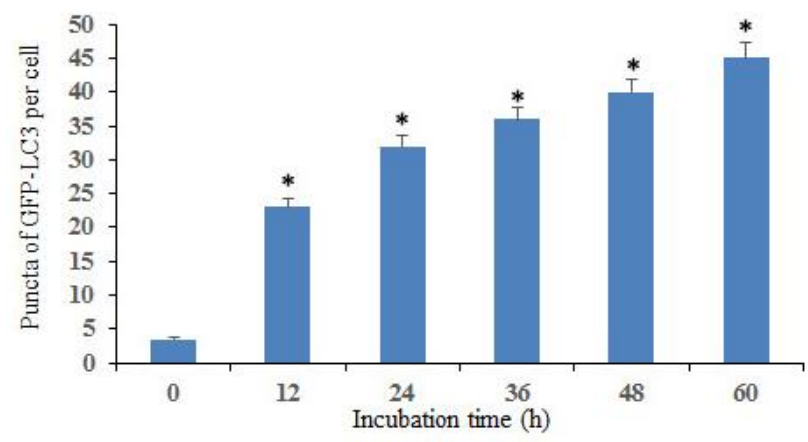

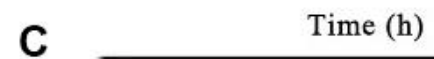
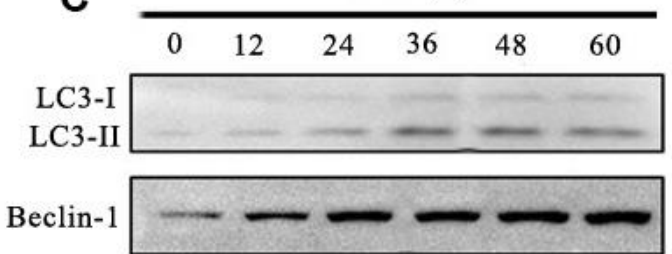

GAPDH

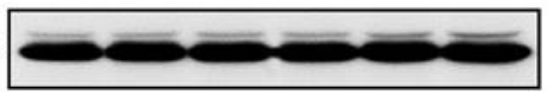

๓LC3-I

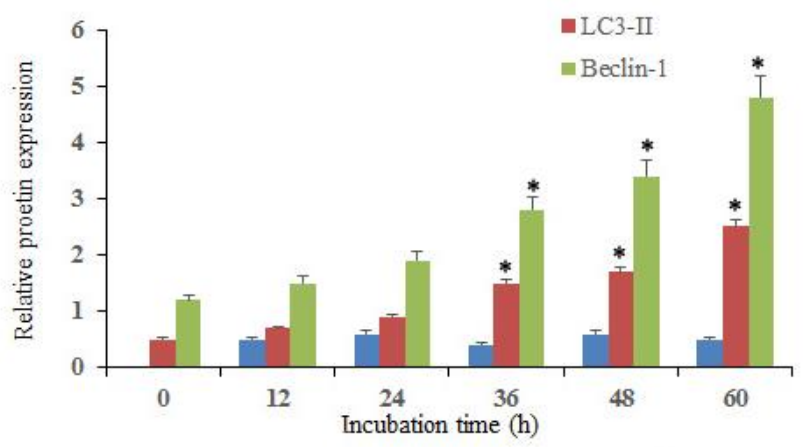

Figure 5. Notch1 induced autophagy in human osteosarcoma cells. (A) Osteosarcoma cells were transiently transfected with GFP-LC3 plasmid for $24 \mathrm{~h}$ and then treated with doxycycline $(10 \mu \mathrm{M})$ for $0,12,24,36,48$ and $60 \mathrm{~h}$. Doxycycline treated cells displayed a punctate pattern of GFP-LC3 expression, which represented formation of autophagosomes. (B) The histogram indicated that autophagy proportion from three separate experiments in different groups. ${ }^{*} \mathrm{P}<0.05$, significantly different compared with the untreated control group. (C) Autophagy-related proteins, LC3 and beclin-1, were analyzed by western blotting. ${ }^{*} \mathrm{P}<0.05$, significantly different compared with the untreated control group. All the experiments were conducted in triplicates. 
arrest and induce apoptosis and autophagy in human osteosarcoma cells. In addition, Notch1 induced apoptosis and autophagy through the inhibition of the $\mathrm{PI} 3 \mathrm{~K} / \mathrm{Akt} / \mathrm{mTOR}$ signalling pathway, which suggested that Notch1-induced autophagy was a pro-survival process. Taken together, our findings provide an alternative strategy of combining regulators of Notch1 expression to treat osteosarcoma.

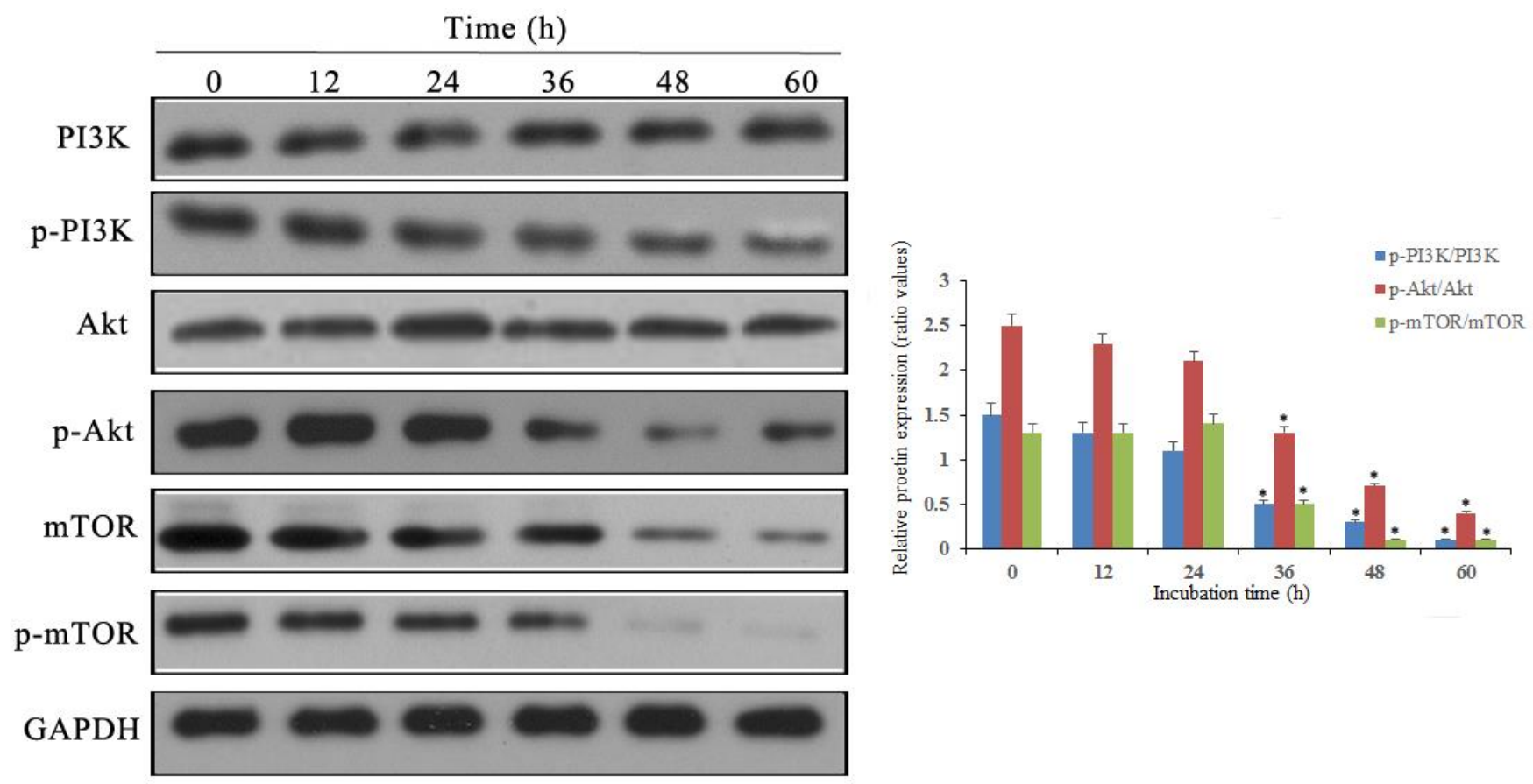

Figure 6. Notch1 induced by doxycycline has blocked PI3K/Akt/mTOR signaling pathway in human osteosarcoma cells. Levels of PI3K, p-PI3K, Akt, p-Akt, mTOR, p-mTOR were analyzed by western blotting. ${ }^{*} \mathrm{P}<0.05$, significantly different compared with the untreated control group. All the experiments were conducted in triplicates.

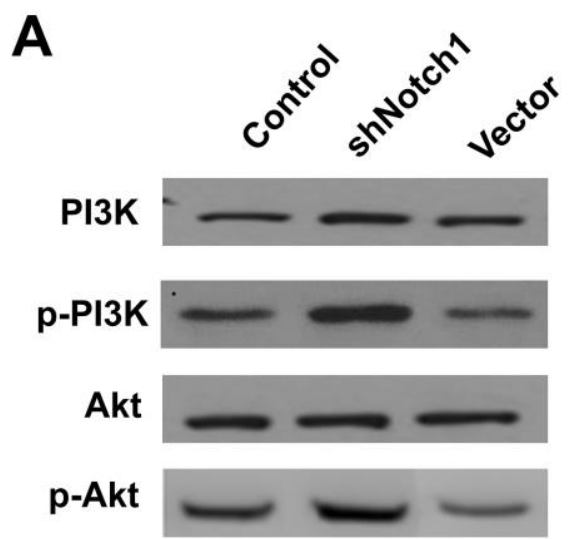

GAPDH
B
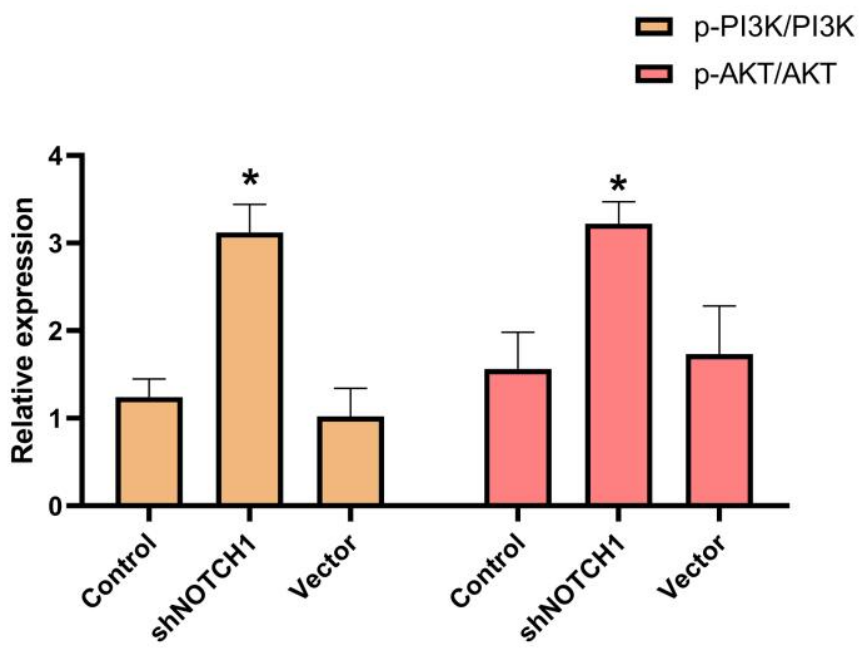

Figure 7. shNotch1 up-regulated the PI3K/Akt signaling pathway in human osteosarcoma cells. (A) The graphs of western blots were present. (B) Levels of PI3K, p-PI3K, Akt and p-Akt were analyzed by western blotting. ${ }^{*} \mathrm{P}<0.05$, significantly different compared with the untreated control group. All the experiments were conducted in triplicates. 


\section{MATERIALS AND METHODS}

\section{Cell lines}

The Notch1-expressing MG-63 cell line, TT-NOTCH1, was established as previously described [10]. Conditional expression of Notch1 was achieved using the TET-ON system. TT-NOTCH1 cells were cultured in DMEM (Thermo Fisher Scientific, MA, USA) supplemented with 5\% FBS (Invitrogen, CA, USA), $100 \mathrm{U} / \mathrm{mL}$ penicillin and $100 \mathrm{pg} / \mathrm{mL}$ streptomycin (Sigma, MO, USA) at $37^{\circ} \mathrm{C}$ in a humidified incubator supplemented with $5 \% \mathrm{CO}_{2}$ and $95 \%$ air.

\section{shNOTCH1 construction}

The plasmid used in this experiment was purchased from Shanghai Jikai Gene Chemical Technology Co., Ltd. The shRNA that silences Notch1 is called shNotch1, and the negative control group is shNotch1NC. Inoculate MG-63 cells in a 6-well plate in advance, follow the transfection instructions to find the most suitable conditions for transfection. After transfection for $48 \mathrm{~h}$, the inhibition efficiency of Notch1 was detected by western blot. The sequences of shNotch1 and control vector were as follows: shNOTCH1: 5'AAGACATGACCAGTGGCTA-3' and the control vector: 5'-TTCTCCGAACGTGTCACGT-3'.

\section{MTT assay}

Cells were subcultured in a 96-well plate at a density of $2 \times 10^{4}$ cells $/ \mathrm{mL}$. Various concentrations of doxycycline $(1.25,2.5,5,10$ and $20 \mu \mathrm{M})$ were added, and the plate was incubated for $24 \mathrm{~h}$. Cell viability was examined using the 3-(4,5-dimethylthiazol-2-yl)-2,5-di-phenyltetrazolium bromide (MTT) assay. Then, $20 \mu \mathrm{L}$ of MTT solution (5 $\mathrm{mg} / \mathrm{mL}$ ) was added into each well and incubated for $4 \mathrm{~h}$. The absorbance at $490 \mathrm{~nm}$ was measured after $150 \mu \mathrm{L}$ of dimethylsulfoxide was added and shaken for $10 \mathrm{~min}$. The cell proliferation curve was then drawn, and the proliferation efficiency was examined. The experiments were repeated three times independently.

\section{Cell cycle analysis}

Cells from different groups were inoculated into 6-well plates at a density of $5 \times 10^{5}$ cells $/ \mathrm{mL}$ and treated for different incubation times $(0,12,24,36,48$ and $60 \mathrm{~h})$ with $10 \mu \mathrm{M}$ doxycycline (DOX) after cell adherence. The cells were collected, centrifuged and washed with PBS, and 70\% ice-cold ethanol was added and incubated overnight. After centrifugation, $150 \mu \mathrm{L}$ of propidium iodide and $150 \mu \mathrm{L}$ of RNase A solution were added for staining for $30 \mathrm{~min}$ at $4^{\circ} \mathrm{C}$ in the dark. BD FACSort Cell Quest software for flow cytometry was used to analyse the cell cycle and obtain cell cycle percentages.

\section{Apoptosis analysis}

Cells were seeded in 6-well plates at a density of $5 \times 10^{5}$ cells $/ \mathrm{mL}$ and treated with $10 \mu \mathrm{M}$ DOX. After incubation, the cells were collected at $0,12,24,36,48$ and $60 \mathrm{~h}$ and washed with ice-cold PBS. Then, binding buffer containing Annexin V-FITC and PI was added to the cells. After being incubated for $15 \mathrm{~min}$ at room temperature in the dark, the samples were analysed by a flow cytometer (BD Biosciences).

\section{Autophagy analysis}

Cells were seeded into 6-well plates at a density of $5 \times 10^{5}$ cells $/ \mathrm{mL}$ and treated with $10 \mu \mathrm{M}$ DOX for $48 \mathrm{~h}$. Then, the cells were incubated with monodansylcadaverine (MDC) for $15 \mathrm{~min}$ and immediately analysed under a fluorescence microscope (Leica Microsystems, Wetzlar, Germany).

\section{Western blotting}

The cells were harvested and lysed on ice for $30 \mathrm{~min}$ in buffer. After centrifugation, the protein concentrations were determined, and the proteins were separated by $10 \%$ sodium dodecyl sulfate-polyacrylamide gel electrophoresis. Then, the proteins were transferred to a polyvinylidene fluoride (PVDF) membrane. After being blocked for $1 \mathrm{~h}$, the membranes were incubated with specific primary antibodies overnight at $4^{\circ} \mathrm{C}$ followed by secondary antibodies for $2 \mathrm{~h}$ at room temperature. Then, the membranes were treated with chemiluminescence reagents (Santa Cruz) per the manufacturer's instructions and analysed by Image $\mathrm{J}$ software.

\section{Statistical analysis}

All statistical analyses were carried out using SPSS 17.0 software (SPSS, IL, USA). All the experiments were conducted in triplicates. The data were presented as the means \pm standard deviation. Differences between two groups were analysed using Student's t-test or chisquare test analysis. One-way ANOVA followed by Kruskal-Wallis $\mathrm{H}$ test was used for multiple comparisons. The results were considered significant when $P$ value $<0.05$.

\section{Availability of data and materials}

The datasets used and/or analyzed during the current study are available from the corresponding author on reasonable request. 


\section{Ethics approval and consent to participate}

The present study was approved by the Institutional Animal Care and Use Committee of The Third Xiangya Hospital Central South University.

\section{Abbreviations}

OS: Osteosarcoma; LC3: light chain 3; Notch1-4: Notch designates a family; mTOR: mammalian target of rapamycin complex; MTT: 3-(4,5-dimethylthiazol-2yl)-2,5-di-phenyltetrazolium bromide; DOX: doxycycline; PI: propidium iodide; MMPs: metalloproteinases.

\section{AUTHOR CONTRIBUTIONS}

SW and KXZ conducted the experiments. HWW participated in the sequence alignment. SW participated in the design of the study and performed the statistical analysis. LL and JHZ conceived of the study, and participated in its design and coordination and helped to draft the manuscript. All authors read and approved the final manuscript.

\section{CONFLICTS OF INTEREST}

Kexiang Zhang, Song Wu, Hongwei Wu, Li Liu, Jiahui Zhou declare that they have no conflict of interest.

\section{FUNDING}

This study was supported by Natural Science Foundation of Hunan Province (NO.2020JJ4861).

\section{REFERENCES}

1. He $\mathrm{H}, \mathrm{Ni} \mathrm{J}$, Huang J. Molecular mechanisms of chemoresistance in osteosarcoma (Review). Oncol Lett. 2014; 7:1352-62. https://doi.org/10.3892/ol.2014.1935 PMID:24765137

2. Mittal N, Kent PM, Ording J. Metastatic and recurrent bone primary bone cancers. Curr Probl Cancer. 2013; 37:215-24.

https://doi.org/10.1016/i.currproblcancer.2013.07.009 PMID:24238587

3. Siegel R, Naishadham D, Jemal A. Cancer statistics, 2013. CA Cancer J Clin. 2013; 63:11-30. https://doi.org/10.3322/caac.21166 PMID:23335087

4. Niswander LM, Kim SY. Stratifying osteosarcoma: minimizing and maximizing therapy. Curr Oncol Rep. 2010; $12: 266-70$. https://doi.org/10.1007/s11912-010-0106-3 PMID:20473649
5. Kroemer G, Mariño G, Levine B. Autophagy and the integrated stress response. Mol Cell. 2010; 40:280-93. https://doi.org/10.1016/j.molcel.2010.09.023 PMID:20965422

6. Song X, Kim SY, Zhang L, Tang D, Bartlett DL, Kwon YT, Lee YJ. Role of AMP-activated protein kinase in crosstalk between apoptosis and autophagy in human colon cancer. Cell Death Dis. 2014; 5:e1504. https://doi.org/10.1038/cddis.2014.463 PMID:25356873

7. Gump JM, Thorburn A. Autophagy and apoptosis: what is the connection? Trends Cell Biol. 2011; 21:387-92. https://doi.org/10.1016/j.tcb.2011.03.007 PMID:21561772

8. He R, Peng J, Yuan P, Xu F, Wei W. Divergent roles of BECN1 in LC3 lipidation and autophagosomal function. Autophagy. 2015; 11:740-47. https://doi.org/10.1080/15548627.2015.1034404 PMID:25955014

9. Singh BN, Kumar D, Shankar S, Srivastava RK. Rottlerin induces autophagy which leads to apoptotic cell death through inhibition of $\mathrm{PI} 3 \mathrm{~K} / \mathrm{Akt} / \mathrm{mTOR}$ pathway in human pancreatic cancer stem cells. Biochem Pharmacol. 2012; 84:1154-63.

https://doi.org/10.1016/i.bcp.2012.08.007

PMID:22902833

10. Kunnimalaiyaan $M$, Vaccaro AM, Ndiaye MA, Chen $H$. Overexpression of the NOTCH1 intracellular domain inhibits cell proliferation and alters the neuroendocrine phenotype of medullary thyroid cancer cells. J Biol Chem. 2006; 281:39819-30.

https://doi.org/10.1074/ibc.M603578200 PMID:17090547

11. Kunnimalaiyaan $\mathrm{M}$, Chen $\mathrm{H}$. Tumor suppressor role of Notch-1 signaling in neuroendocrine tumors. Oncologist. 2007; 12:535-42.

https://doi.org/10.1634/theoncologist.12-5-535 PMID:17522241

12. Li L, Zhang J, Xiong N, Li S, Chen Y, Yang H, Wu C, Zeng $\mathrm{H}$, Liu $\mathrm{Y}$. Notch-1 signaling activates NF-KB in human breast carcinoma MDA-MB-231 cells via PP2A-dependent AKT pathway. Med Oncol. 2016; 33:33.

https://doi.org/10.1007/s12032-016-0747-7 PMID:26945854

13. Cornejo MG, Mabialah V, Sykes SM, Khandan T, Lo Celso C, Lopez CK, Rivera-Muñoz P, Rameau P, Tothova Z, Aster JC, DePinho RA, Scadden DT, Gilliland DG, Mercher T. Crosstalk between NOTCH and AKT signaling during murine megakaryocyte lineage specification. Blood. 2011; 118:1264-73. https://doi.org/10.1182/blood-2011-01-328567 PMID:21653327 
14. Palomero $T$, Sulis $M L$, Cortina $M$, Real PJ, Barnes $K$, Ciofani M, Caparros E, Buteau J, Brown K, Perkins SL, Bhagat G, Agarwal AM, Basso G, et al. Mutational loss of PTEN induces resistance to NOTCH1 inhibition in Tcell leukemia. Nat Med. 2007; 13:1203-10.

https://doi.org/10.1038/nm1636 PMID:17873882

15. Palomero $T$, Dominguez $M$, Ferrando AA. The role of the PTEN/AKT Pathway in NOTCH1-induced leukemia. Cell Cycle. 2008; 7:965-70.

https://doi.org/10.4161/cc.7.8.5753 PMID:18414037

16. Bo Q, Ma S, Han $Q$, Wang FE, Li X, Zhang Y. Role of autophagy in photoreceptor cell survival and death. Crit Rev Eukaryot Gene Expr. 2015; 25:23-32. https://doi.org/10.1615/critreveukaryotgeneexpr.2015 012376 PMID:25955815

17. Wan G, Tian L, Yu Y, Li F, Wang X, Li C, Deng S, Yu X, Cai $X$, Zuo Z, Cao F. Overexpression of Pofut1 and activated Notch1 may be associated with poor prognosis in breast cancer. Biochem Biophys Res Commun. 2017; 491:104-11.

https://doi.org/10.1016/j.bbrc.2017.07.053 PMID:28709865

18. Pinchot SN, Jaskula-Sztul R, Ning L, Peters NR, Cook MR, Kunnimalaiyaan $M$, Chen $H$. Identification and validation of Notch pathway activating compounds through a novel high-throughput screening method. Cancer. 2011; 117:1386-98.

https://doi.org/10.1002/cncr.25652 PMID:21425138

19. Truong M, Cook MR, Pinchot SN, Kunnimalaiyaan M, Chen H. Resveratrol induces Notch2-mediated apoptosis and suppression of neuroendocrine markers in medullary thyroid cancer. Ann Surg Oncol. 2011; 18:1506-11.

https://doi.org/10.1245/s10434-010-1488-z

PMID:21184191

20. Yao J, Duan L, Fan M, Yuan J, Wu X. Notch1 induces cell cycle arrest and apoptosis in human cervical cancer cells: involvement of nuclear factor kappa B inhibition. Int J Gynecol Cancer. 2007; 17:502-10. https://doi.org/10.1111/i.1525-1438.2007.00872.x PMID: 17316355

21. Greenblatt DY, Cayo MA, Adler JT, Ning L, Haymart MR, Kunnimalaiyaan $\mathrm{M}$, Chen $\mathrm{H}$. Valproic acid activates Notch1 signaling and induces apoptosis in medullary thyroid cancer cells. Ann Surg. 2008; 247:1036-40. https://doi.org/10.1097/SLA.0b013e3181758d0e PMID:18520232

22. Zeng $Y$, Yin B, Wang X, Xia G, Shen Z, Gu W, Wu M. Effects of the Notch1 signaling pathway on human lung cancer A549 cells. Exp Lung Res. 2017; 43:208-16. https://doi.org/10.1080/01902148.2017.1341008 PMID:28718726
23. Ouyang L, Shi Z, Zhao S, Wang FT, Zhou TT, Liu B, Bao JK. Programmed cell death pathways in cancer: a review of apoptosis, autophagy and programmed necrosis. Cell Prolif. 2012; 45:487-98.

https://doi.org/10.1111/j.1365-2184.2012.00845.x PMID:23030059

24. Yao J, Zheng K, Li C, Liu H, Shan X. Interference of Notch1 inhibits the growth of glioma cancer cells by inducing cell autophagy and down-regulation of Notch1-Hes-1 signaling pathway. Med Oncol. 2015; 32:610.

https://doi.org/10.1007/s12032-015-0610-2 PMID:25920606

25. Zhang L, Wang $\mathrm{H}, \mathrm{Xu} \mathrm{J,} \mathrm{Zhu} \mathrm{J,} \mathrm{Ding} \mathrm{K.} \mathrm{Inhibition} \mathrm{of}$ cathepsin $\mathrm{S}$ induces autophagy and apoptosis in human glioblastoma cell lines through ROS-mediated $\mathrm{PI3K} / \mathrm{AKT} / \mathrm{mTOR} / \mathrm{p} 70 \mathrm{S6K}$ and JNK signaling pathways. Toxicol Lett. 2014; 228:248-59.

https://doi.org/10.1016/i.toxlet.2014.05.015 PMID:24875536

26. Zhang $Y$, Liu $Y$, Zou J, Yan L, Du W, Zhang $Y$, Sun $H$, Lu $P$, Geng S, Gu R, Zhang H, Bi Z. Tetrahydrocurcumin induces mesenchymal-epithelial transition and suppresses angiogenesis by targeting HIF-1 $\alpha$ and autophagy in human osteosarcoma. Oncotarget. 2017; 8:91134-49.

https://doi.org/10.18632/oncotarget.19845 PMID:29207631

27. Li HY, Zhang J, Sun LL, Li BH, Gao HL, Xie T, Zhang N, Ye ZM. Celastrol induces apoptosis and autophagy via the ROS/JNK signaling pathway in human osteosarcoma cells: an in vitro and in vivo study. Cell Death Dis. 2015; 6:e1604.

https://doi.org/10.1038/cddis.2014.543 PMID:25611379

28. Wang BY, Cao J, Chen JW, Liu QY. Triptolide induces apoptosis of gastric cancer cells via inhibiting the overexpression of MDM2. Med Oncol. 2014; 31:270. https://doi.org/10.1007/s12032-014-0270-7 PMID:25280518

29. Wang $G$, Zhang $T$, Sun $W$, Wang $H$, Yin $F$, Wang $Z$, Zuo D, Sun M, Zhou Z, Lin B, Xu J, Hua Y, Li H, Cai Z. Arsenic sulfide induces apoptosis and autophagy through the activation of ROS/JNK and suppression of Akt/mTOR signaling pathways in osteosarcoma. Free Radic Biol Med. 2017; 106:24-37.

https://doi.org/10.1016/j.freeradbiomed.2017.02.015 PMID:28188923

30. Wu C, Yan D, Lu D, Han T, Zhao B. Alteration of the $\mathrm{PI3K} /$ Akt signaling pathway by swainsonine affects $17 \beta$-Estradiol secretion in ovary cells. Theriogenology. 2017; 103:123-29. 
https://doi.org/10.1016/i.theriogenology.2017.07.033 PMID:28780483

31. Keta O, Bulat T, Golić I, Incerti S, Korać A, Petrović I, Ristić-Fira A. The impact of autophagy on cell death modalities in CRL-5876 lung adenocarcinoma cells after their exposure to $\gamma$-rays and/or erlotinib. Cell Biol Toxicol. 2016; 32:83-101.

https://doi.org/10.1007/s10565-016-9319-z

PMID:27026538

32. Ryter SW, Mizumura K, Choi AM. The impact of autophagy on cell death modalities. Int J Cell Biol. 2014; 2014:502676.

https://doi.org/10.1155/2014/502676

PMID:24639873
33. Zaarour RF, Azakir B, Hajam EY, Nawafleh H, Zeinelabdin NA, Engelsen AST, Thiery J, Jamora C, Chouaib S. Role of Hypoxia-Mediated Autophagy in Tumor Cell Death and Survival. Cancers (Basel). 2021; 13:533.

https://doi.org/10.3390/cancers13030533

PMID:33573362

34. Su M, Mei Y, Sinha S. Role of the Crosstalk between Autophagy and Apoptosis in Cancer. J Oncol. 2013; 2013:102735.

https://doi.org/10.1155/2013/102735

PMID:23840208 